\begin{tabular}{|l|l|}
\hline $\begin{array}{l}\text { Postprint } \\
\text { Version }\end{array}$ & 1.0 \\
\hline Journal website & http://onlinelibrary.wiley.com/doi/10.1111/j.1365-2788.2011.01472.x/full \\
\hline Pubmed link & http://www.ncbi.nlm.nih.gov/pubmed/21955287 \\
\hline DOI & $10.1111 /$ j.1365-2788.2011.01472.x. \\
\hline
\end{tabular}

This is a NIVEL certified Post Print, more info at http://www.nivel.eu

\title{
People with mild to moderate intellectual disability talking about their diabetes and how they manage
}

\author{
M. CARDOL ${ }^{1, *}$, M. RIJKEN ${ }^{1}$, H. VAN SCHROJENSTEIN LANTMAN-DE VALK ${ }^{2}$ \\ ${ }^{1}$ NIVEL (Netherlands Institute for Health Services Research), Utrecht, The Netherlands \\ ${ }^{2}$ Department of Primary and Community Care; Radboud University Nijmegen Medical Centre, \\ Nijmegen, The Netherlands
}

\begin{abstract}
Background: The prevalence of diabetes is relatively high in people with intellectual disability (ID). However, little is known about how people with ID experience having diabetes and how they manage the condition.

Method: Seventeen people with mild to moderate ID who have diabetes were interviewed. A framework on illness perceptions having an influence on diabetes self-management was used as a basis for the interviews and for the qualitative analysis.

Results: Diabetes is associated with feelings of loss with regard to food intake and choices, and with being controlled. Most respondents did not feel ill. Information about diabetes for people with ID is lacking, but they do have questions. Family members with diabetes often serve as a role model. Diabetes self-management is impeded by a lack of information, motivation and support, few opportunities for learning, and by health factors, mood and living accommodation. Communication between health professionals and people with ID about diabetes rarely takes place.

Conclusions: Developing diabetes information together with the people concerned is an important step towards engagement in self-management activities. At the same time, the professional staff in living arrangements should stimulate and support the development of selfmanagement skills in people with diabetes, by providing opportunities to learn and develop. Therefore, the professional staff also need skills and information to be able to support people with ID in building the skills and confidence they need to lead active and fulfilling lives, despite having diabetes.
\end{abstract}

\section{INTRODUCTION}

The prevalence of diabetes in the general adult population is estimated at 6\% (World Diabetes Foundation 2011). People with intellectual disability (ID) face an increased risk of diabetes as compared to the general adult population. Some of the syndromes of people with ID are clearly linked to diabetes, such as Down syndrome and Prader-Willi syndrome, as well as conditions of overweight that frequently occur in people with ID (Anwar et al. 1998; van Schrojenstein Lantman-de Valk et al. 2000; Butler et al. 2002; Henderson et al. 2007). In a Dutch study concerning people with ID a prevalence of $11 \%$ was found (Straetmans et al. 2007). In adults with Prader-Willi syndrome, a prevalence of $25 \%$ was found (Butler et al. 2002). 
Diabetes is a chronic disease that arises when the pancreas does not produce enough insulin, or when the body cannot effectively use the insulin it produces. Type 1 is called insulin-dependent diabetes. It usually occurs in children or young adults. People with type 1 diabetes need insulin injections several times a day. Type 1 diabetes is estimated to be up to 35 times more common in people with ID (Anwar et al. 1998). Type 2 diabetes is characterised by insulin resistance and relative insulin deficiency. The diagnosis of type 2 diabetes usually occurs after the age of 40 years but could occur earlier, especially in populations with high diabetes prevalence. Type 2 diabetes is common in people with ID, but exact estimates of its prevalence are lacking. People with type 2 diabetes take oral medication and receive instructions regarding their diet and exercise. If this does not help, insulin is needed.

\section{Diabetes perceptions and management}

People with diabetes have their own beliefs about the condition (Skelton \& Croyle 1991) that are reflected in illness perceptions. Illness perceptions are organised around five key questions (Hagger \& Orbell 2003): what is it, how long will it last, what caused it, how has it affected me and can it be controlled or cured? Beliefs about diabetes vary: for one person, diabetes may seem a minor condition, whereas another may see diabetes as a condition with serious consequences. The Common Sense Model of Leventhal argues that these illness perceptions are associated with the way people cope with their illness (Leventhal et al. 1997). Differences in perceptions result in different management strategies (Kaptein et al. 2007). Studies in people without ID show that individuals who perceive their illness to have serious consequences experience greater distress and have more difficulties in coping (Hagger \& Orbell 2003). A better self-reported understanding of diabetes is associated with greater adherence to diet and fewer negative feelings associated with the disease (Farmer et al. 2006; Searle et al. 2007a).

Management of diabetes takes place mainly at home. It consists of taking medication but also of adopting lifestyle changes and dealing with the medical and psychosocial consequences of the disease. People manage diabetes in different ways and one person may do a better job than another from a health perspective. Diabetes self-management involves knowledge about diabetes, the skills to do a blood test or to inject insulin, and a feeling of self-efficacy to use the knowledge. Also for people who are not able to manage the illness themselves, some personal control or choice over daily activities is essential for quality of life and a person's engagement in activities (Stancliffe 1997; Koritsas et al. 2008; Stancliffe et al. 2008).

\section{What is already known}

Although diabetes prevalence is high in people with ID, little is known about how they experience having diabetes and how they manage it. In an Australian study in nine adults with ID and diabetes it was concluded that a lack of knowledge about diabetes makes it difficult for people to function in an effective and satisfactory way (Rey-Conde 2006; Rey-Conde \& Lennox 2007). Another study of 10 people with ID found that diabetes was perceived to be an intrusion in their lives, especially with regard to food intake (Nesbitt 2006). Both studies indicated a need for useful information.

Understanding health information is described in a relatively new construct, called health literacy. Health literacy not only applies to people with ID, but also to groups such as the elderly and those who are not proficient in the dominant language of their country of residence (Easton et al. 2010). The definition goes beyond understanding information leaflets: 'Health literacy is the degree to which individuals can obtain, process, understand and communicate about health-related information needed to make informed health decisions' (Berkman et al. 2010).

In the present study, we will explore the diabetes perceptions of people with ID in the Netherlands. Innovative to this study is that we use Leventhal's perceptions framework and that we also examine how people manage diabetes and how they communicate with health professionals about diabetes.

The research questions are:

What perceptions of diabetes do people with mild or moderate ID have?

What factors are related to the self-management of the disease?

\section{PATIENTS AND METHODS}

\section{Procedure}

Although many publications discuss diabetes perceptions, little is known about diabetes perceptions and self-management of diabetes among people with ID. To address this, a qualitative methodology was used in 
this work. This research is part of a larger study in which people with ID and diabetes, their relatives and professional staff were interviewed. In this paper, we report about the interviews with the people with diabetes in their homes.

Leventhal's Common Sense Model was used as a basis for the interview and for the qualitative analysis (Leventhal et al. 1997; Broadbent et al. 2006). Accordingly, the interview protocol incorporated the five key questions outlined above in the Introduction: beliefs about the symptoms, duration and consequences, perceived knowledge, beliefs about controlling diabetes and the effectiveness of treatment. The interview protocol was developed together with a person with ID, the Dutch diabetes association (Diabetes Vereniging Nederland) and the Dutch association for people with ID (Platform VG). During the interviews pictographs were used for clarification of the question asked. All interviews were completed by the first author (M. C.). Almost all interviews lasted 40 to $60 \mathrm{~min}$.

\section{Participants}

Participants for this study were recruited among the members of the 'Living Together' Panel. This is a national panel of people with mild to moderate ID in the Netherlands, that is, representative as far as age, gender and the distribution of people with mild and moderate disabilities are concerned (Box 1) (Dusseljee et al. 2010). The 'Living Together' Panel is registered with the Dutch Data Protection Authority, and the data were collected according to the privacy protection guidelines of the Authority. Persons who met the selection criteria for this study were informed about the research by means of oral and written information and were asked to participate. According to Dutch law, ethical approval was unnecessary for this study since it regarded a non-interventional design. All participants gave their informed consent to participate in the study.

At the time of this study, in 2010, the panel consisted of 630 people with ID. At least 24 members with ID, or their relatives, had reported having diabetes. One person did not want to talk about his condition. After 17 interviews we had reached the point at which no new information or themes were observed in the data (saturation). The interviews were conducted with eight men and nine women. According to their relatives, seven individuals had a mild ID and another seven had a moderate ID; the level of ID of the other three persons is unknown. Twelve respondents had had diabetes for about 5 years or longer, five for a shorter period. Eight of the interviewed respondents used insulin, six used oral medication and three managed their diabetes by diet alone. Two participants lived in a residential facility, eight lived in community housing and seven had a place of their own, with or without support. All participants that lived independently had a mild ID. The average age of the participants in this study was 52 years, ranging from 32 to 70 years.

\section{Analysis}

The interviews were recorded and the tapes were transcribed verbatim. The perceptions of diabetes as described in the illness perceptions framework formed the basis of the analyses, although there was room to add or change concepts or to develop new concepts that would better fit the lived experiences of people with ID and diabetes. Thematic analysis was conducted using strategies from grounded theory (Corbin \& Strauss 2008). In the first phase of the analysis, groupings of similar phenomena were allocated conceptual labels (open coding), for example, 'consequences of having diabetes for food intake'. In the second phase (axial coding) subordinate concepts were categorised under broader level concepts. For example, 'understanding' and 'occasion' were categorised under 'self-management of diabetes'. Data analysis was iterative so that the later interviews enabled us to test and further explore themes from the initial analysis. A team of two researchers (M. C., M. R.) discussed the codes and made comparisons until agreement was reached on all codes. Using the criteria from the discussion process as a guide, the primary author then completed the analysis. The software package MaxQDA 2007 was used to analyse the data (Kuckartz 2007).

\section{RESULTS}

\section{Theme 1: feelings of loss with regard to food intake and choices}

Most of the 17 respondents did not know what caused their diabetes; it came on suddenly and without warning. Others mentioned being overweight or having family members with diabetes. Most respondents did not know that different types of diabetes exist. Often the professional staff and their relatives also did not know whether the respondent had diabetes type 1 or 2 . 
When asked what diabetes is, almost all respondents mentioned the practical consequences of diabetes for daily life. The most prominent consequence involves feelings of loss with regard to food intake. Not being allowed to eat and drink as and when you like is difficult. The wordings 'must not', 'cannot' and 'should not' were dominant in the descriptions of diabetes.

Often you are hungry, but you are not allowed to give in. Waffles are delicious, especially warm. Ooh their sweet taste . . . but you must not give in (man, community housing, insulin, 44 years).

Yes, for me it was very difficult to have it [diabetes]. I can't have this, I can't have that (woman, community housing, insulin, 63 years).

Respondents living in community housing reported more loss. They were more often confronted with seeing other people eating and they noticed differences in food intake between fellow house mates and themselves.

I get the same as the others, but always less (woman, community housing, no insulin, 50 years). Diabetes negatively affects opportunities and choices in life, such as not being able to go on the holiday you want to, or spontaneously stay for dinner somewhere. They asked me to stay for dinner, but I couldn't because I didn't have my insulin with me. That's a real pity, a chance to eat with someone else for once (man, community housing, insulin, 44 years).

There is some variety though, in the reported loss. Two men said that the diabetes did not have an effect on their daily life whatsoever. One lived in a residential facility and had handed all the diabetes management over to the professional staff. In answer to the question what is diabetes, he advised the interviewer to talk with the staff. The other man lived independently. He used insulin but was happy he could eat what he liked.

\section{Theme 2: medication and control}

Another consequence of diabetes involved the blood glucose tests and, if needed, the insulin injections. It is about control, isn't it, pricking your finger with a needle and then they check the device to see how much, how high it is (man, independent, no insulin, 65 years).

Most people say they became familiar with the tests and injections, but they do not like them because they can hurt or because they are afraid of the needle. One man showed the length of the needle with his hands: about $1 \mathrm{~m}$. Another man: 'I saw that woman with her needles, I pushed the assistant away and ran off to my room, yelling' (man, community housing, no insulin, 38 years). Some respondents had strong preferences for the site of the injection but this was not always acted upon: 'I want it in my legs, not in my belly. In the hospital they did it in my belly and I didn't like that. I don't like it in my belly, I don't know, I think it's frightening' (woman, independent, insulin, 57 years). Another woman said she liked to have the injection in her belly, because of the softness of the skin of the belly as compared to the leg.

Taking pills was not an issue immediately associated with diabetes. Most respondents took pills for various conditions, and they perceived taking pills to be a part of daily life.

Strikingly, more than once, diabetes was described as a thing or an entity inside the body. One woman compared it with a stranger that is harmless, but only if you take care: 'It's inside your body, you can't see it ... it lives together with you. If you don't take care, you get ill' (woman, community housing, no insulin, 70 years).

\section{Theme 3: not feeling ill}

Diabetes is seen as a serious and chronic condition only if insulin injections are needed. Often, a family member was used as a reference for one's own health status. 'My sister has diabetes too, but she has type 1 diabetes. With all those injections and everything. In my case it's not that bad' (man, independent, no insulin, 63 years).

Most respondents did not feel ill and their health was not a major concern. Being overweight on the other hand often was. 'I worry about my weight. I am too heavy. And if I get heavier, I'll have more trouble with it [diabetes]' (woman, independent, no insulin, 50 years).

For the respondents it was difficult to differentiate between symptoms due to diabetes, for example, tiredness, and symptoms related to other health conditions such as heart failure or aging. A few respondents said they could feel when their glucose level was too high, but this was not experienced as frightening or serious. The symptoms related to diabetes mentioned by the respondents were mostly related to a low blood glucose level and described as feeling 'shaky', 'not clear in my head' or 'slow'. Those who had experienced an acutely low blood glucose level were familiar with the accompanying symptoms very well, because it 
had been a frightening experience: 'I almost faded away, that is a serious feeling, you know, like you are dying, fading away, that's no fun I can tell you' (man, community housing, insulin, 44 years).

\section{Theme 4: unanswered questions}

With regard to the emotional impact of diabetes, in first instance, most respondents said they had got used to it. They felt sorry for others with diabetes. After further questioning, almost all respondents reported feeling sad about having it or expressed concern and persistent worry about the future. Respondents in community housing more often reported concerns and fearful thoughts.

Yes, how to get rid of it? I don't know, I don't like it, but even so, I have it, you get used to it and then it's not so bad, but still if I think I want to get rid of it I start crying (woman, community housing, no insulin, 34 years).

I am concerned whether I will live long. Can you tell me, can you grow old with it [diabetes]? (man, community housing, insulin, 44 years).

For consolation, some people try not to think about diabetes. A few respondents living in community housing spoke about certain 'advantages' to having diabetes: they get more attention from the professional staff and can choose what to eat, whereas other residents of the living accommodation cannot.

\section{Theme 5: check-ups without asking questions}

None of the respondents expressed perceptions related to the effects of treatment. They all attended the general practitioner or hospital when they were told to, but hardly ever asked questions about diabetes. They tend to regard these visits as check-ups: [When you are at the doctor's, do you sometimes ask questions about diabetes?]'I wouldn't dare to, he asks me all the time, no, I wouldn't dare to talk about that myself. I am not afraid of it, oh no, but I wouldn't dare.' (man, community housing, insulin, 69 years).

Once a year I get a thorough check-up. The same as with you, talking and being checked out. (man, community housing, no insulin, 41 years).

Being accompanied to the health professional by relatives or professional staff was very much appreciated by the respondents because the health information could be explained later on.

Self-management occurs in varying degrees of knowledge and action. Several issues of influence were identified by the respondents. Understanding diabetes, motivation for self-management and special occasions are related to the intention to self-manage, whereas support by professionals and significant others can encourage, while health factors, mood and contextual factors can impede self-management (Fig. 1).

\section{[FIGURE 1].}

Theme 6: intentions to self-management are related to understanding, motivation and special occasions

With regard to food intake, the respondents generally had practical knowledge, although they did not fully understand why they could not eat what and when they wanted. Nevertheless, this practical knowledge gave them a grip in daily life. 'Diabetes says: two sandwiches and one cream cracker only' (woman, community housing, insulin, 55 years).

There seems to be a relationship between a better understanding of diabetes and more self-management, but not in all respondents and not on all occasions. 'I cannot have too much sugar. Look, I don't put sugar in my coffee, but sometimes a tiny little bit, just for the taste' (woman, community housing, no insulin, 34 years). For respondents who understand more about the disease, it seemed easier to think of alternatives to make healthier choices.

I like to drink lemonade, but try to add as much water as possible (woman, independent, no insulin, 50 years).

None of the respondents had received written diabetes information they could understand. Nevertheless, they had questions. Close relatives with diabetes are important resources for diabetes knowledge and skills. 'I don't have questions about diabetes, I have my mom' (man, independent, no insulin, 44 years).

With regard to self-management, a person's motivation seems more important than the severity of the ID. Some respondents were in general more interested in health matters than others, but respondents that were involved in self-management activities seemed more aware of their diabetes and more motivated to selfmanage diabetes as far as they could. For example, the professional staff told one respondent when to inject insulin and set the units for injection, but the respondent injected herself. Another respondent always 
arranged the things needed for the injection (a tea towel, clean spot on the table). Both showed pride in these accomplishments.

In the interviews, all respondents referred to special occasions when it is not necessary to be strict. These occasions involve all kinds of celebrations, weekends or having visitors. 'At the weekends I can spoil myself for once, on weekdays it's better not to’ (man, community housing, insulin, 44 years).

Theme 7: self-management is related to feelings of self-efficacy, support, health condition, mood and contextual factors

Besides understanding, confidence in one's own abilities is important for using knowledge and developing self-management skills. The respondents did not talk about their own confidence in a direct way, but their narratives showed that professionals and significant others are important resources for gaining confidence and developing skills. In the community housing not all respondents had opportunities to learn to become self-confident; in many cases the professional staff took over. They supported the respondents in preparing for hospital check-ups and explained the information given afterwards, but hardly provided any opportunities to learn to live with and manage diabetes at home. If available, family members with diabetes are the most important resource for learning how to deal with the medical and psychosocial consequences of the disease. Family members with or without diabetes are important too for consolation or positive feedback. 'Well, we talk about how you feel and ... , you know, whether something still bothers you. That's nice. She knows all about it too, you know.' (woman, community housing, insulin, 63 years).

The respondent's health condition or age made it more difficult to recognise symptoms and to self-manage them. Other health conditions also inhibited daily exercise. 'This week I exercised to keep fit, yesterday, but yes, that arm, they have tried, but it does not work. Massage and all. It's terrible.' (woman, community housing, insulin, 63 years).

The respondent's mood can make it more difficult to self-manage. For example, when you feel down or lonely, it is harder to stick to the diet.

Furthermore, financial problems or transportation problems prevented some respondents from making healthy choices, for example, with regard to exercise. 'I used to play football, but the busses changed. It's too difficult to get there' (man, community housing, no insulin, 38 years). Finally, for a number of respondents communal living arrangements made self-management more difficult, because of tight daily structures, communal meals and the temptations involved in seeing other people eat.

\section{DISCUSSION}

This study shows that people with ID who have diabetes are aware that they have it. They have their own beliefs about their illness and its management. With regard to living with diabetes, five major themes were identified. For people with ID diabetes is strongly related to consequences for daily life, as also shown in two other studies (Nesbitt 2006; Rey-Conde 2006). In general the people with ID and diabetes do not feel ill, but they have learned that to avoid illness they must take care. And in different ways they do so. Our study offers more detailed information about the management of diabetes. The intention to manage diabetes is related mainly to a person's understanding of diabetes, motivation for self-management and the occasion. However, intentions to manage can be tempered by a lack of support, few opportunities to learn, health factors, mood and contextual factors such as the living accommodation. Having diabetes in communal living arrangements seems more difficult to handle. For people with ID, self-management activities associated with diabetes involve lifestyle changes related to food intake and taking medication. Communication with health professionals about diabetes did not really seem to take place.

It is important to note that the results of this study concern people with mild or moderate ID who were able to communicate. However, only one person with diabetes did not want to be interviewed. Additionally, we could not distinguish between people with type 1 and type 2 diabetes, because this information was unknown. Instead, we were able to make comparisons between people who used insulin and those who did not.

The perceptions of people with ID about the severity of diabetes resemble those of people without ID who have diabetes: they both believe that diabetes is a serious illness especially if you have to take insulin (Searle et al. 2007b). Also the dilemmas regarding knowing versus doing have been described in studies of people with diabetes without ID (Polly 1992; Koch et al. 2000; Thoolen et al. 2007). For example, they knew what they could and could not eat, but in many situations it was difficult to act on this knowledge. 
With regard to Leventhal's Common Sense Model, in which it is argued that illness perceptions are associated with the way people cope with diabetes, we did find some support for the hypothesis that people who perceive diabetes as a serious illness perform greater self-management activities (Polly 1992), but only among respondents who lived alone. This observation was related to a greater understanding and more opportunities for self-management behaviour, such as seeking alternatives to non-healthy food. In addition, our study shows that attention for facilitating and impeding factors for self-management is important, but situational differences that have an impact on the translation from illness perceptions to self-management are not part of Leventhal's framework.

Several authors already stated that the provision of information about diabetes that people can understand is important (Nesbitt 2006; Rey-Conde \& Lennox 2007; Lennox et al. 2009). Only well informed people can engage in self-management and be more in control. As yet, people with ID seem dependent on the professional staff in the living arrangements and on family members to obtain this information. None of the people with ID had received information about diabetes that they could understand. The respondents in this study already mention themes that are important to include in such information. Besides information on diabetes itself, important issues include alternatives to things you should not eat, answers to concerns, occasions for not being strict, how to get motivated to engage in self-management activities and information about factors that facilitate self-management. At the University of Queensland, Australia, a website was developed for people with ID and diabetes that can serve as an example for other countries (Lennox et al. 2009). Additional information on the website about living with diabetes that does not focus on medical aspects, however, would make the website even more powerful.

Based on the results of this study we can add that people also need room and opportunities to learn and to use the available knowledge. As such, developing diabetes information that people can understand is one step. The main difference in the diabetes self-management of people with ID as compared to people without ID is that often a caregiver or professional staff has a main role in supporting the management of diabetes. Accordingly, the self-management of the person with diabetes strongly relies on professionals' and relatives' perceptions and knowledge of diabetes. From this study, it seems that the respondents mainly received diabetes information related to food intake and medication. However, from the interviews it appears that their thoughts and concerns go beyond this practical and medical information. Therefore, relatives and the professional staff in the living arrangements also need skills and information to be able to support people with ID in building the skills and confidence needed to lead active lives, despite diabetes. This involves knowledge about diabetes, skills to engage with patients as partners in care and a clientcentred attitude to provide opportunities for learning and self-development.

\section{CONCLUSION}

This study must be considered as an explorative work on diabetes and its management in people with ID. Nevertheless, it already provides directions to support people with ID who have diabetes. Development of information about diabetes that people can understand is an important step towards self-management. This step should be taken together with the persons who have diabetes in a participatory research design. However, diabetes information is only a means to engage people in managing their illness and to talk about it. This next step, engagement in self-management and developing self-confidence to use the information learned, should also be undertaken.

\section{ACKNOWLEDGEMENTS}

The authors of this study wish to thank all the persons who were willing to participate in this research, and the Dutch Diabetes Research Foundation for its financial support.

\section{REFERENCES}

Anwar A. J., Walker J. D. \& Frier B. M. (1998) Type 1 diabetes mellitus and Down's syndrome: prevalence, management and diabetic complications. Diabetic Medicine 15, 160-3.

Berkman N. D., Davis T. C. \& McCormack L. (2010) Health literacy: what is it? Journal of Health Communication 15, 9-19.

Broadbent E., Petrie K. J., Main J. \& Weinman J. (2006) The brief illness perception questionnaire. Journal of Psychosomatic Research 60, 631-7. 
Butler J. V., Whittington J. E., Holland A. J., Boer H., Clarke D. \& Webb T. (2002) Prevalence of, and risk factors for, physical ill-health in people with Prader-Willi syndrome: a population based study.

Developmental Medicine and Child Neurology 44, 248-55.

Corbin J. \& Strauss A. (2008) Basics of Qualitative Research; Techniques and Procedures for Developing Grounded Theory. Sage Publications, Thousand Oaks, CA.

Dusseljee J. C. E., Rijken P. M., Cardol M., Curfs L. M. G. \& Groenewegen P. P. (2010) Participation in daytime activities among people with mild or moderate intellectual disability. Journal of Intellectual Disability Research 55, 4-18.

Easton P., Entwistle V. A. \& Williams B. (2010) Health in the 'hidden population' of people with low literacy. A systematic review of the literature. BMC Public Health 10, 459.

Farmer A., Kinmonth A.-L. \& Sutton S. (2006) Measuring beliefs about taking hypoglycaemic medication among people with Type 2 diabetes. Diabetic Medicine 23, 265-70.

Hagger M. S. \& Orbell S. (2003) A meta-analytic review of the common-sense model of illness representations. Psychology and Health 18, 141-84.

Henderson A., Lynch S. A., Wilkinson S. \& Hunter M. (2007) Adults with Down's syndrome: the prevalence of complications and health care in the community. British Journal of General Practice 57, 50-5.

Kaptein A., Korlaar I. M., Cameron L., Vossen C. Y., Van der Meer F. J. M. \& Rosendaal F. R. (2007) Using the common-sense model to predict risk perception and disease-related worry in individuals at increased risk for venous thrombosis. Health Psychology 26, 807-12.

Koch T., Kralik D. \& Taylor J. (2000) Men living with diabetes: minimizing the intrusiveness of the disease. Journal of Clinical Nursing 9, 247-54.

Koritsas S., Iacono T., Hamilton D. \& Leighton D. (2008) The effect of active support training on engagement, opportunities for choice, challenging behaviour and support needs. Journal of Intellectual \& Developmental Disability 33, 247-56.

Kuckartz U. (2007) Max Qualitative Data Analysis; Reference Manual. Verbi Software, Marburg.

Lennox N., Rey-Conde T., McPhee J. \& Taylor M. (2009) The development and evaluation of resources about diabetes management for people with intellectual disability and their care providers. Journal on Developmental Disabilities 15, 77-80.

Leventhal H., Benyamini Y., Brownlee S., Diefenbach M., Leventhal E. A. \& Patrick-Miller L. (1997) Illness representations: theoretical foundations. In: Perceptions of Health and Illness: Current Research and Applications (eds K. J. Petrie \& J. A. Weinman), pp. 19-46. Harwood Academic, Amsterdam.

Nesbitt A. (2006) The lived experience of an intellectual disability and diabetes mellitus. Unpublished Work. Polly R. K. (1992) Diabetes health beliefs, self-care behaviors, and glycemic control among older adults with non-insulin-dependent diabetes mellitus. The Diabetes Educator 18, 321-7.

Rey-Conde T. (2006) Living with diabetes and an intellectual disability (2006). Conquest Winter, 25.

Rey-Conde T. \& Lennox N. (2007) Delivering diabetes care to people with intellectual disability. Diabetes Voice 52, 16-8.

van Schrojenstein Lantman-de Valk H. M., Metsemakers J. F. M., Soomers-Turlings J. M. S. J. G., Haveman M. J. \& Crebolder H. F. J. M. (1997) People with intellectual disabilities in general practice: case definition and case finding. Journal of Intellectual Disability Research 41, 373-9.

van Schrojenstein Lantman-de Valk H. M., Metsemakers J. F. M., Haveman M. J. \& Crebolder H. F. J. M. (2000) Health problems in people with intellectual disability in general practice: a comparative study. Family Practice 17, 405-7.

Searle A., Norman P., Thompson R. \& Vedhara K. (2007a) A prospective examination of illness beliefs and coping in patients with type 2 diabetes. British Journal of Health Psychology 12, 621-38.

Searle A., Norman P., Thompson R. \& Vedhara K. (2007b) Illness representations among patients with type 2 diabetes and their partners: relationships with self-management behaviors. Journal of Psychosomatic Research 63, 175-84.

Skelton J. A. \& Croyle R. T. (1991) Mental Representation in Health and Illness. Springer-Verlag, New York.

Stancliffe R. J. (1997) Community living-unit size, staff presence, and residents' choice-making. Mental Retardation 35, 1-9.

Stancliffe R. J., Harman A. D., Toogood S. \& McVilly K. R. (2008) Staff behaviour and resident engagement before and after active support training. Journal of Intellectual \& Developmental Disability 33, 257-70.

Straetmans J. M. J. A. A., van Schrojenstein Lantman-De Valk H. M. J., Schellevis F. G. \& Dinant G. (2007) Health problems of people with intellectual disabilities: the impact for general practice. British Journal of General Practice 57, 64-6.

Thoolen B. J., De Ridder D. T. D., Bensing J., Gorter K. J. \& Rutten G. E. H. M. (2007) No impact, no worries? In: Beyond Good Intentions. The Effectiveness of a Proactive Self-Management Intervention in 
Cardol, M., Rijken, M., Schrojenstein Lantman-de Valk, H. van. People with mild to moderate intellectual disability talking about their diabetes and how they manage. Journal of Intellectual Disability Research:2012 56(4), 351-360

Patients with Screen-Detected Type 2 Diabetes (ed. B. J. Thoolen), pp. 12-37. Thesis University of Utrecht, Utrecht.

World Diabetes Foundation (2011). Diabetes Facts.

http://www.worlddiabetesfoundation.org/composite35.htm (retrieved February 2011)

\section{BOX AND FIGURES}

Box I 'Living Together' Panel: why, who and what?

$\rightarrow$ The panel started in 2006 to monitor the social and community participation of people with intellectual disability (ID).

$\rightarrow$ People with ID and a close relative can become members of the panel. Members of the panel were recruited randomly from 87 general practices and from 55 Dutch care organisations for people with ID. The recruitment in general practices was conducted on the basis of a method to identify people with ID in general practice (van Schrojenstein Lantman-de Valk et al. I997)

$\rightarrow$ The members with ID live independently (with or without professional care), in small living arrangements or in larger institutions, spread throughout the country.

$\rightarrow$ Every 2 years the people with ID are interviewed about their participation in society, social support, health and quality of life. Every year, the relatives are asked to complete a postal questionnaire about the same subjects from their point of view.

Figure 1 Factors of influence on diabetes self-management identified by 17 adults with intellectual disability and diabetes.

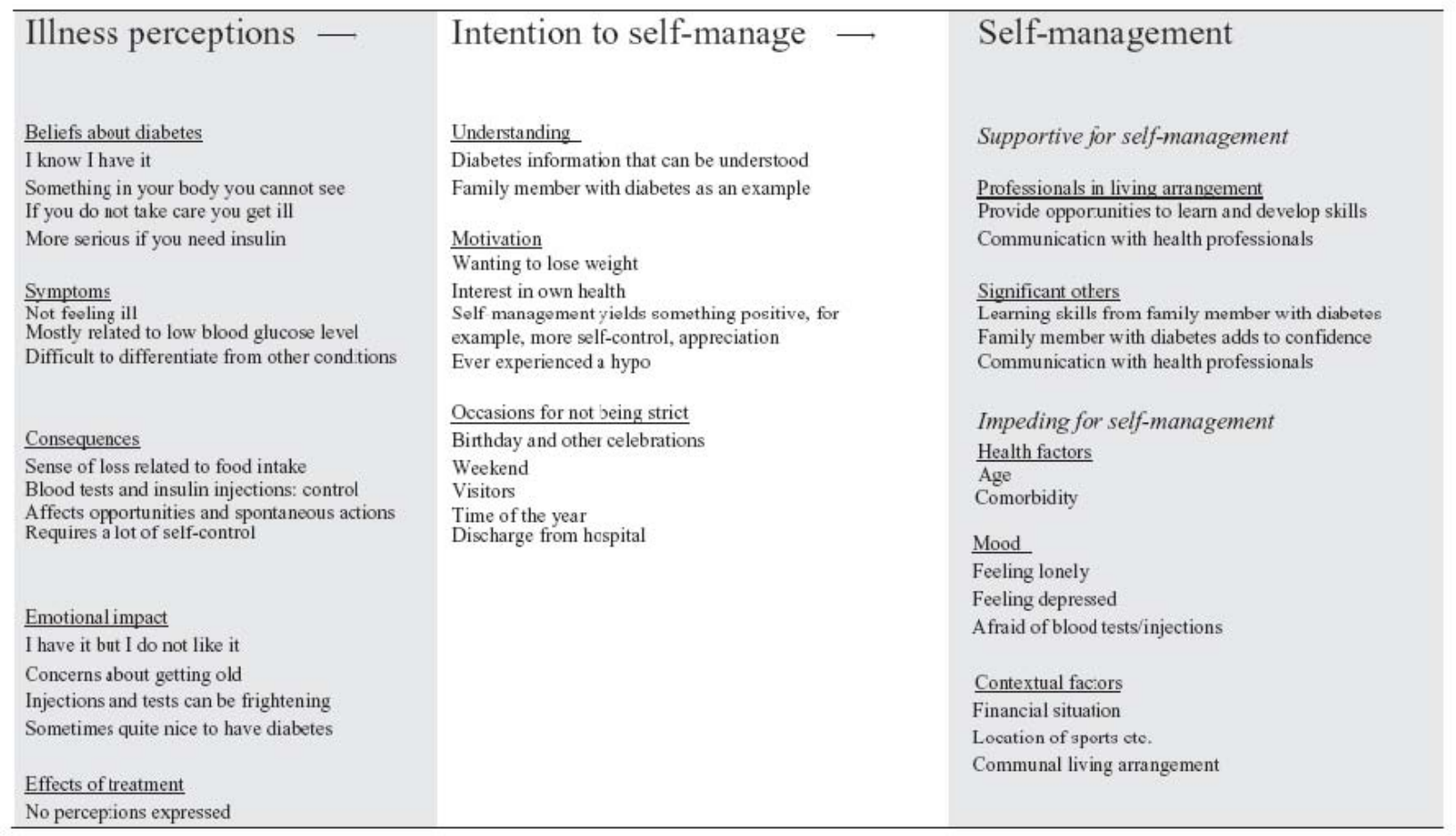

